\title{
Design of a Smart Tool for Knowledge Management in R\&D Projects
}

\author{
Amaigarou Noureddin \\ Laboratory of Computer Science Operational \\ Research and Applied Statistics \\ Abdelmalek Essaadi University, Faculty of Science, \\ Tetouan, Morocco B.P. 209 Martil, Morocco
}

\author{
Mohamed Khaldi \\ Laboratory of Computer Science Operational \\ Research and Applied Statistics \\ Abdelmalek Essaadi University, Higher Normal \\ School, Tetouan, Morocco B.P. 209 Martil, Morocco
}

\begin{abstract}
This paper deals with the representation of ontology-based knowledge and its use in multi-agent systems. Basing on topic interest and that knowledge has immense value in all kinds of businesses and in people's daily lives and also in the elearning field.

The research presented in this paper aims to establish a stronger link between Knowledge Management Knowledge (KM) and Multi-Agent Systems (MAS), using ontology as tools. design and definition of knowledge and the semantic web as a space for production and reuse.
\end{abstract}

\section{Keywords}

Multi-Agent Systems, Knowledge, Experience, Ontology, CommonKADS, R \& D

\section{INTRODUCTION}

Knowledge management (KM) and multi-agent systems (MAS) are relatively new areas of research and are still growing. The technology of the agents seemed very favorable since it gives a new paradigm for software technologies and especially technology dedicated to learning and decision support.

Recent technologies such as SOAP, WSDL, UDDI or Peer-toPeer are also a result of MAS (Muti-agent Systems) but are only partial achievements of the MAS potential. KM (Knowledge Management) \& Ontologies on the other hand have already succeeded in the field of semantic Web.

The work presented in this article aims to establish a stronger link between KM and MAS, mainly by integrating the work done in the semantic web at MAS.

Agent technology uses and exploits the results of all areas of artificial intelligence, such as learning, negotiation or knowledge management. This thesis focuses on one of them the use of KM by agent systems, which makes it possible to develop an architecture adapted to the many fields of application.

In this paper, we show a use of the work described in the thesis in a pilot project. We mainly discuss the use and evaluation of results in a research and development project using our SATIJ application.

\section{PRESENTATION OF SATIJ}

The overall goal of this project was to develop an adaptable platform to help mobile employees at the organizational level, in fact to restructure their work in an organization. This will improve the efficiency and effectiveness of the organization through the formalization, recording, storage and preservation of experience and knowledge; and support workers when integrating into a new department or role by providing access to specific knowledge and experience accumulated in the past. On the technical side, the goal is to develop and integrate several advanced technologies into a customizable agentbased architecture. These technologies include autonomous cooperation agents; reactive interaction with end users; organizational memory; modeling workflows and processes; and metadata to access document repositories. Another goal is to gain experience in personalization and formulate best practice guidelines for using the platform to help mobile workers at the organizational level.

\section{TEST ENVIRONMENT}

The particular problem of our organization is the wide range of tasks that its employees have to deal with. They include management of common services (such as recycling, cultural projects), provision of innovation and technology services (such as identification of opportunities and weaknesses in the region), support for business initiatives, etc.

The objectives of this organization are:

- Activities to support job creation and improve the standard of living of the population

- Promote a change in the productive systems of local communities towards activities with comparative advantages in national and international markets

- Create transport and communication infrastructure and services needed to support the development of local economies

- Administer economic and financial aid to promote production and build infrastructure and services.

- Coordinate initiatives and collaborate with agents involved in regional development projects in the region.

- A project management procedure has been selected as a representative workflow process in this organization. 


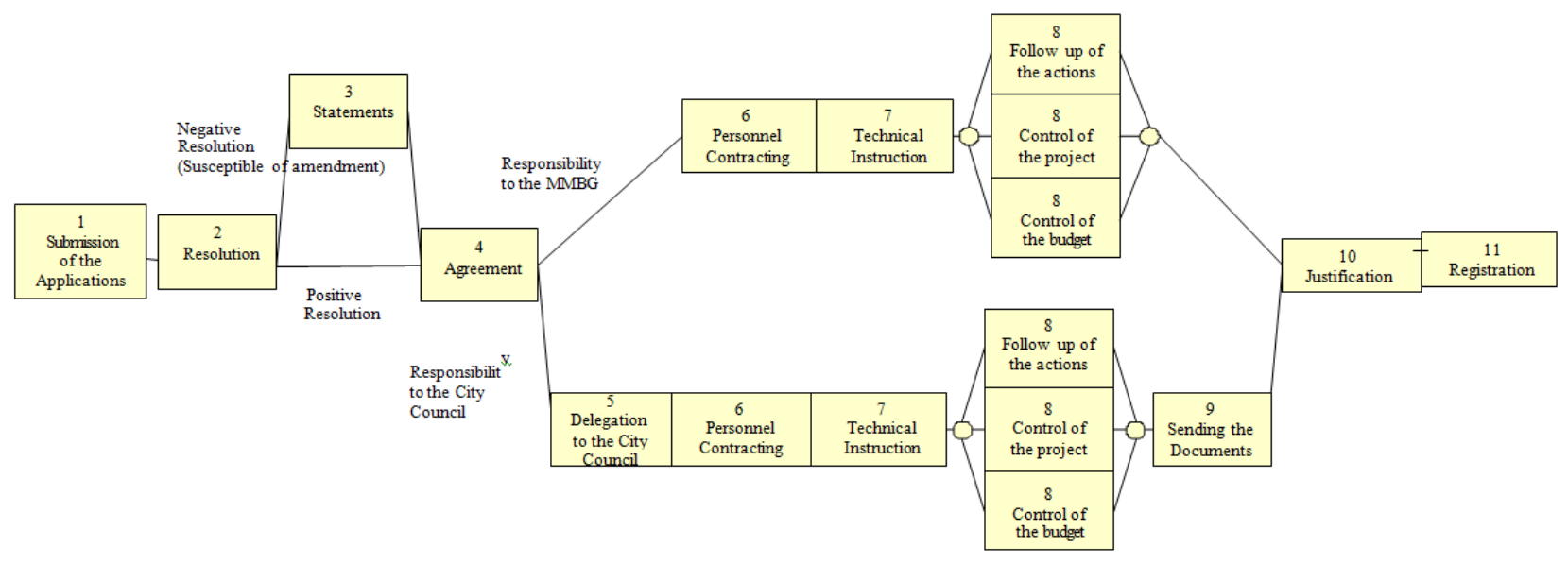

Figure 1 : Pilot Project - Project and Service Management

\section{SYSTEM SPECIFICATION AND DESIGN}

The architecture consists of several main elements (see Figure 2).

Agents (A) - the core of the system, tracking, reasoning and interfacing;

- Organizational Memory (OM) - the history of the organization used by agents;

- organizational repositories - document repositories (in the broad sense) available as part of work processes;

- Workflow Management / Tracking System (WfMS / WfTS);

- Web Server (HTTPD) - which integrates SATIJ with WfMS / WfTS via the web interface.

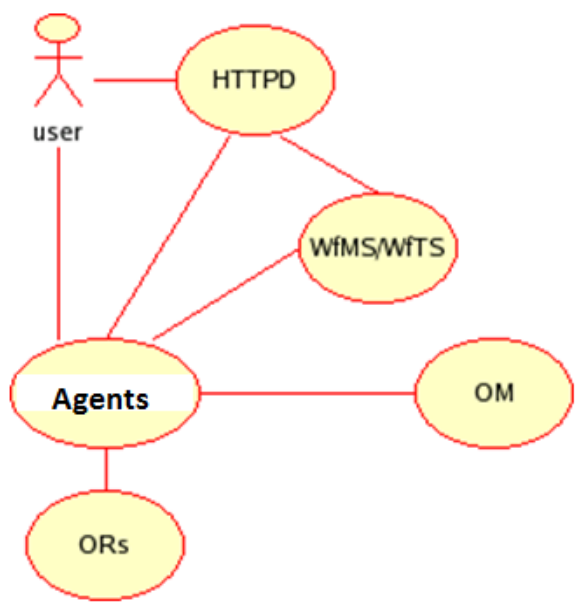

Figure 2: Basic architecture diagram

\section{SATIJ PROJECT AGENT}

Different approaches to combine the SATIJ user interface with that of WfMS / WfTS can be implemented. In a template, all requests can be directed to a special web server. The web server will request information from both WfMS / WfTS and SATIJ Personal Assistant Agents. Once the web server has received a complete response from both systems, it connects both parties and creates the final Web output. The connection is based on templates.
The Workflow Management System (WFMS) reports the current workflow activities (process steps) or other events that occur in the system to the monitoring agent, using XMLbased PRC.

In this section, the functionality of the SATIJ agents is briefly described.

SATIJ agent types:

- Supervisory Agent (MA)

- Information Retrieval Agent (ISA)

- Capitalization Agent (CA)

- Role Agent (RA)

- task agent (TA)

- Personal Assistant Agent (PAA)

The monitoring agent provides an interface to receive information about events that have occurred in the employee environment, primarily from WfMS / WfTS, repository monitors, or email monitoring. The Information Retrieval Agent (ISA) is activated by RA to search for information resources (documents and contacts) using ontological metadata. The Capitalization Agent says new facts when reviewing historical OM data. It performs data mining on the $\mathrm{OM}$ to find, organize and store global knowledge. RA is associated with an employee role within an organization and is linked to a workflow process. The RA provides Wf related information to the AAP and handles simple AAP queries. The RA collects relevant information directly from the MO or indirectly by using TA and ISA. The RA serves several PAAs. It is an intelligent agent knowing the associated role. The task agent is activated by the registration authority to search for knowledge related to a certain activity in the workflow. It handles complex and / or long requests from the RA. The PAA provides an interface between a user (employee) and the SATIJ agents. The PAA transmits the user's request to obtain knowledge from the RA and processes the information received from RA / TA / ISA. It presents personalized information to a user. There is one PAA per user.

The UML sequence diagram (Figure 3 and Figure 4) shows how the information between elements of the SATIJ architecture is exchanged. By elements we mean agents, a web server, WfMS / WfTS and organizational memory. 
Several sequence diagrams illustrating the message transmission scheme have been created based on the methodology defined later:

- $\quad$ Action executed in the WfMS / WfTS user interface
- Action executed in the SATIJ user interface for a better understanding of the sequence diagrams, see the table below.

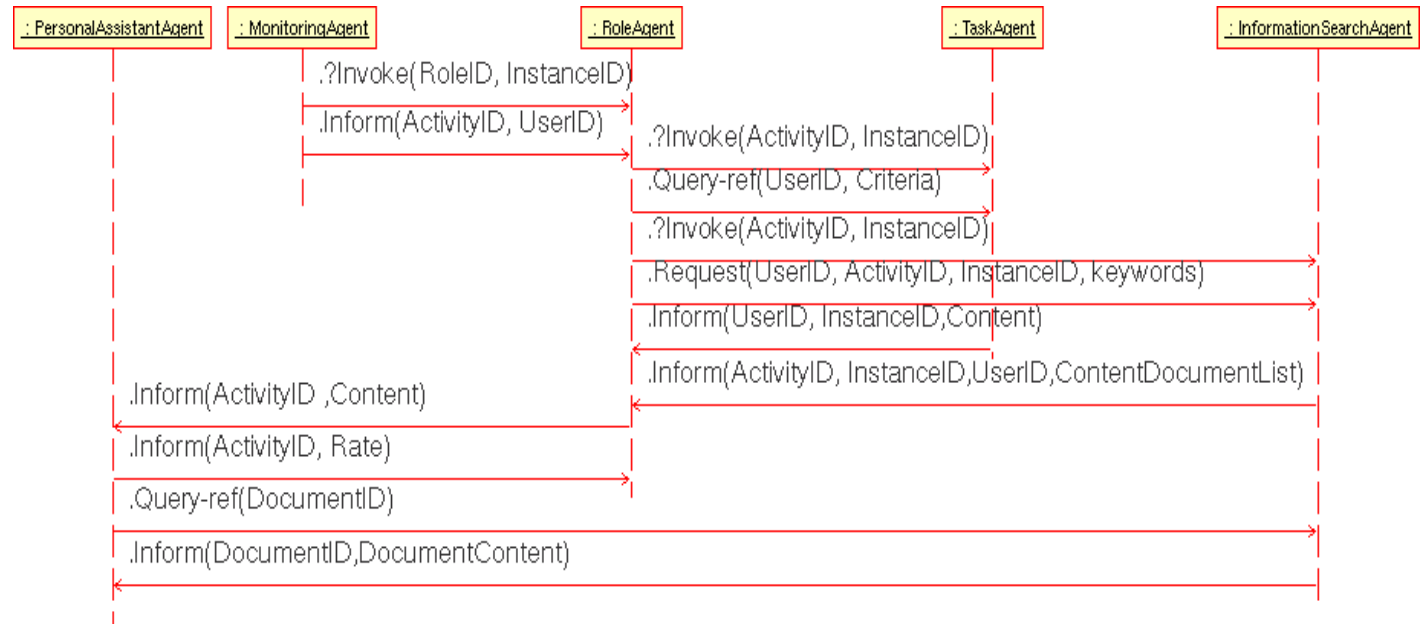

Figure 3: UML sequence diagram -Action taken in the WfMS / WfTS user interface

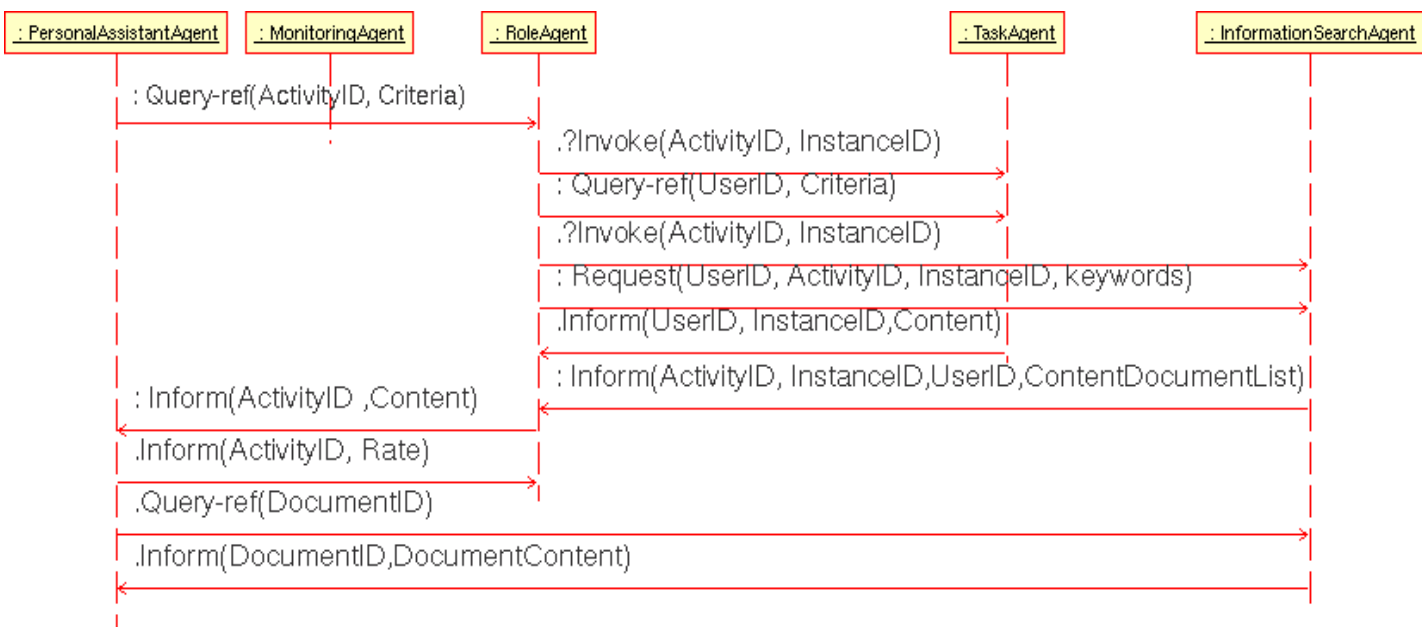

Figure 4 : UML sequence diagram -Action taken in the SATIJ user interface

\begin{tabular}{|c|c|c|c|c|}
\hline From & To & $\begin{array}{c}\text { Message } \\
\text { type }\end{array}$ & Content & Purpose \\
\hline MA & RA & Inform & activityID, userID & $\begin{array}{c}\text { Informing about activities } \\
\text { in workflow }\end{array}$ \\
\hline RA & TA & Query-ref & userID, criteria & $\begin{array}{c}\text { Requesting the TA to provide the RA with } \\
\text { info related to the Activity }\end{array}$ \\
\hline RA & ISA & Request & userID, ActivityID, \\
InstanceID, keywords & $\begin{array}{c}\text { Requesting the ISA to } \\
\text { perform } \\
\text { actions on }\end{array}$ \\
\hline
\end{tabular}




\begin{tabular}{|c|c|c|c|c|}
\hline TA & RA & Inform & UserID, Content & $\begin{array}{l}\text { Returns information } \\
\text { related with an activity such as relevant } \\
\text { contact list etc. }\end{array}$ \\
\hline ISA & RA & Inform & $\begin{array}{c}\text { UserID, ActivityID, } \\
\text { InstanceID, DocumentList }\end{array}$ & $\begin{array}{l}\text { Returns } \\
\text { document list to the RA }\end{array}$ \\
\hline RA & PAA & Inform & ActivityID, Content & $\begin{array}{l}\text { Inform the PAA with all useful info } \\
\text { related to an activity such as a contact list, } \\
\text { or a document list. }\end{array}$ \\
\hline PAA & RA & Inform & ActivityID, Rating & $\begin{array}{c}\text { Inform the RA about a user rating on } \\
\text { contacts, documents or other useful } \\
\text { information. }\end{array}$ \\
\hline PAA & ISA & Query-ref & DocumentID & $\begin{array}{c}\begin{array}{c}\text { Request the ISA for returning a particular } \\
\text { document }\end{array}\end{array}$ \\
\hline ISA & PAA & Inform & $\begin{array}{c}\text { DocumentID, } \\
\text { DocumentContent }\end{array}$ & Returns document \\
\hline PAA & RA & Query-ref & ActivityID, Criteria & $\begin{array}{c}\text { The PAA requests the RA to return } \\
\text { information related to the activity in } \\
\text { relation to certain criteria (ontological } \\
\text { question) }\end{array}$ \\
\hline Any & Any & Not- understood & - & $\begin{array}{c}\text { When an agent gets an unexpected } \\
\text { understandable message. }\end{array}$ \\
\hline
\end{tabular}

\section{ONTOLOGY OF THE PROJECT MANAGEMENT DOMAIN}

The ontology of the project management domain mainly defines concepts related to different types of documents, as well as concepts associated with the project (instance of problem process or workflow), such as a theme, a type or a line of action of the project. These concepts are reported in events and then processed by algorithms for updating resources and context. In addition, some of them are used for similarity calculations. 


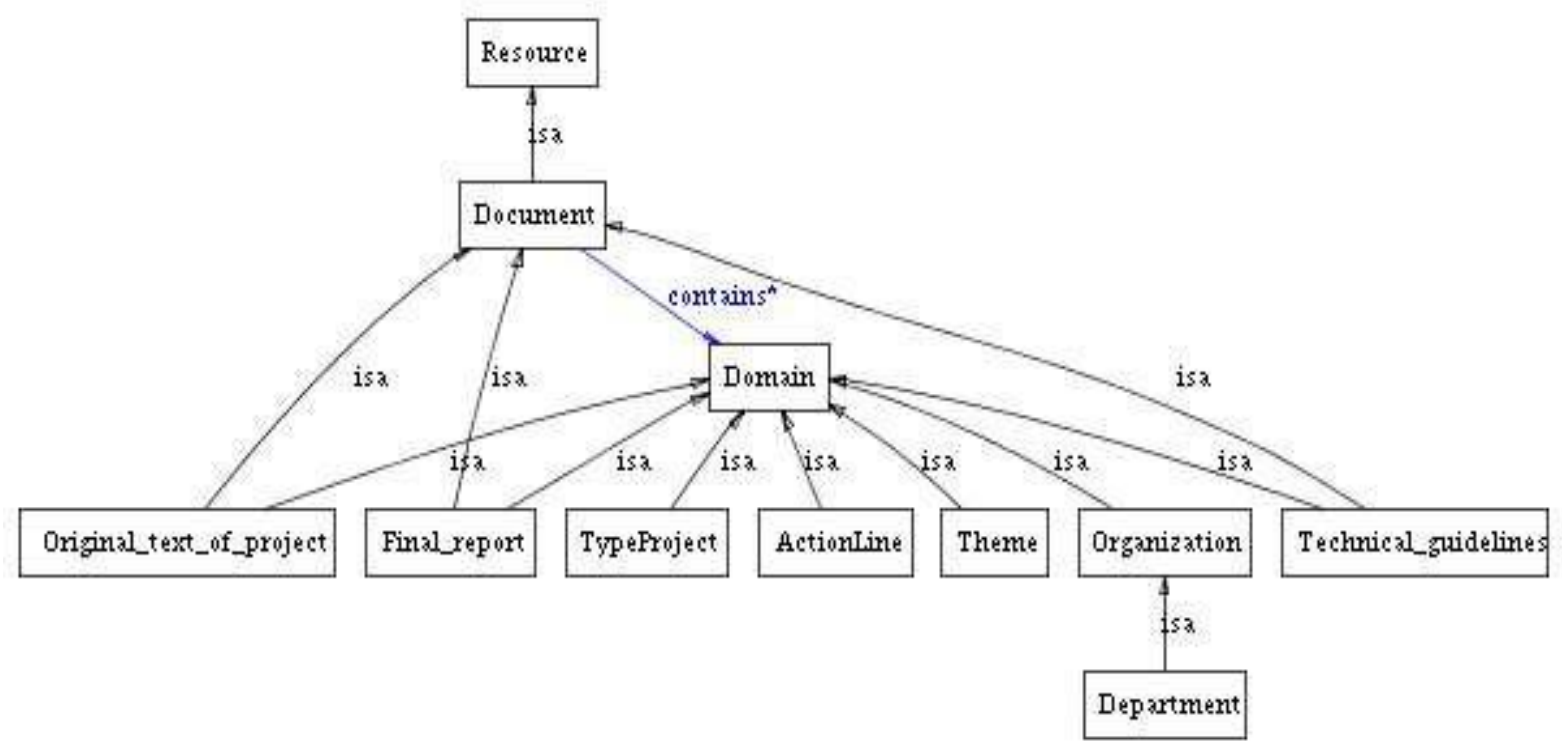

Figure 5: Key Concepts of the Project Management Ontology

\section{SIMILARITY METHODS USED IN}

\section{SATIJ}

Two of the SATIJ applications used the approach described in Chapter 5 regarding similarity measures for the context of the problem. The main idea was to return relevant resources (in this case, the experience in the form of active guidance) from a context similar to the current user context. The proposed system made it possible to define a large number of similarity types providing measures of similarity between different resources. As mentioned in Chapter 5, we have developed a generic similarity method based on similarity weights that can be defined in an ontology model. Such a method could be used simply by weight definition in an ontology, redrawn to include other properties or to use totally independent similarity methods. The three options were used in the SATIJ project.

\section{PROJECT MANAGEMENT SIMILARITY FUNCTIONS}

The project management application has adopted similarity measures based on similarity weights (Figure 6) explained later, where a line of action, a type of project, and a processing service are the most significant concepts of the project. similarity of the project.

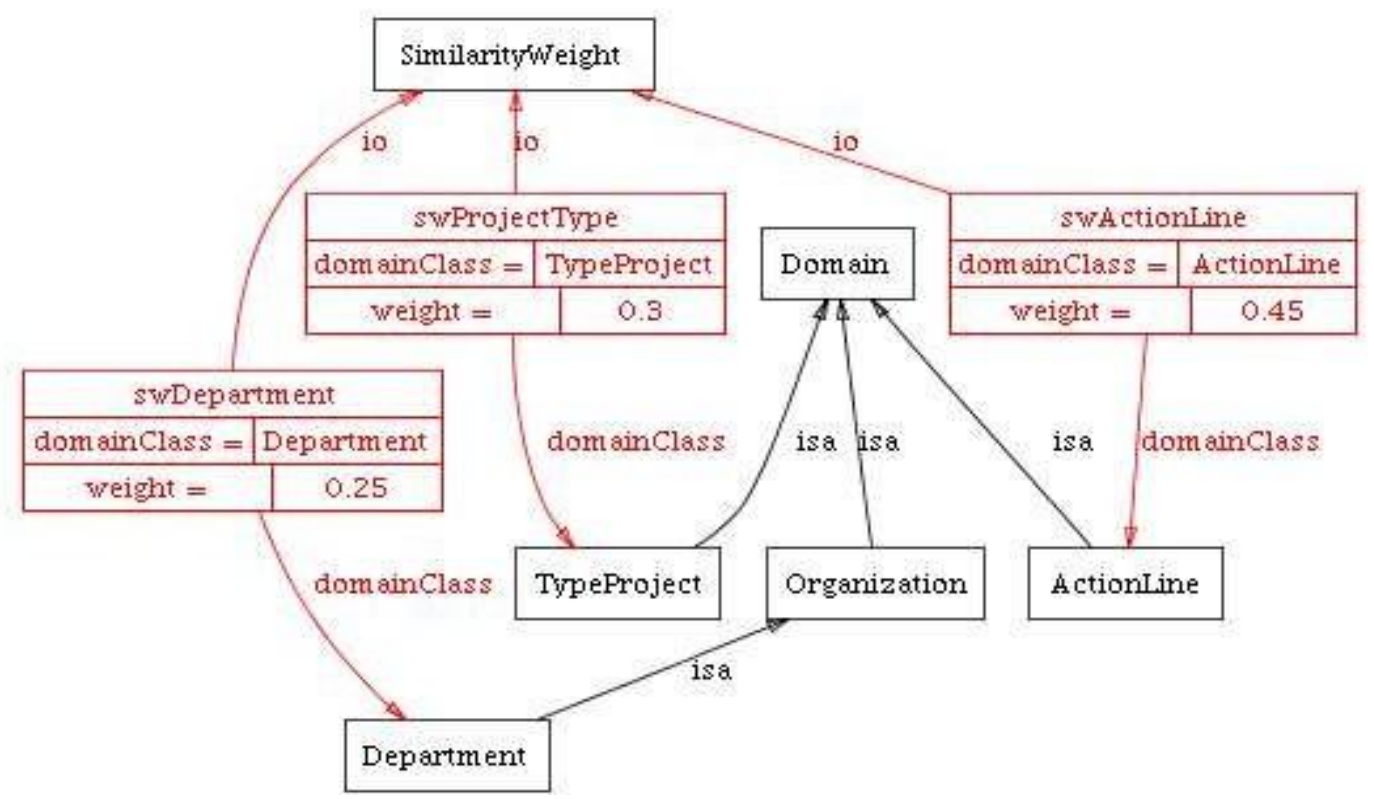

Figure 6: Similarity weight in the project management application 


\section{CONCLUSION}

The SATIJ project provided a huge opportunity to test and evaluate the results presented in our research. The agent memory model, the knowledge-based agent modeling methodology, the knowledge model for managing experiences with context update algorithms and stakeholder resources (active indicators) were used, tested and successfully tested in the SATIJ project.

\section{REFERENCES}

[1] Bowman, M., Debray, S. K., and Peterson, L. L. 1993. Reasoning about naming systems.

[2] [LUCK, 2003]: Michael Luck, Peter McBurney, Chris Preist, Agent Technology:Enabling Next Generation Computing, A Roadmap for Agent Based Computing, 2003

[3] [MASKADS]: Carlos A. Iglesias , Mercedes Garijo , Jose C. Gonzalez, Juan R. Velasco, Analysis and Design of Multiagent Systems using MAS-CommonKADS, , 1998

[4] [NGU, 2004]: NGUYEN G.T., LACLAVÍK M., BALOGH Z., GATIAL E., HLUCHÝ

[5] L., DANG T.T, BUDINSKÁ I., SATIJ - Platform for Organisational Public Emploees, ICETA 2004. 3rd International Conference on Emerging Telecommunications Technologies and Applications. Kosice ELFA,2004

[6] [OBIT, 2004]: Marek Obitko, Vladimir Marík, OWL Ontology Agent based on FIPA

[7] proposal, Znalosti 2004, Brno, Czech Republic,2004

[8] [OILED]: , Ontology Editor: OilEd, 2004, http://oiled.man.ac.uk/

[9] [OMGWEB]: OMG Group, OMG Group Website, 2005, http://www.omg.org/

[10] [ONTOVIZ]: Michal Sintek, OntoViz Tab: Visualizing Protégé Ontologies, 2004, http://protege.stanford.edu/plugins/ontoviz/ontoviz.html

[11] [ONTOWEB]: Ontoweb Consortium, Ontoweb Portal, 2002, http://www.ontoweb.org/

[12] [OWLGUIDE]: W3C, OWL Web Ontology Language Guide, 2004, http://www.w3.org/TR/owl-guide/

[13] [OWLWEB]: W3C, Web Ontology Language OWL, 2004, http://www.w3.org/TR/owl-features/

[14] [PROTKADS]: Guus Schreiber, Monica Crubezy, Mark Musen, A Case Study in Using Protege-2000 as a Tool for CommonKADS, ,2001

[15] [PROTWEB]: Stanford University, Protégé Ontology Editor, 2004,

[16] http://protege.stanford.edu/

[17] [RDFDBWEB]: , rdfDB Query Language, 2004, http://guha.com/rdfdb/query.html

[18] [RDFW3C]: W3C, Resource Description Framework RDF, 2004, http://www.w3.org/RDF/
[19] [SLOTA, 2003]: R. Slota, M. Majewska, M. Dziewierz, K Krawczyk, M. Laclavik, Z. Balogh, L. Hluchy, J. Kitowski, S. Lambert, Ontology Assisted Access to Document Repositories for Public Sector Organizations, PPAM 2003, Czestochowa, Poland,2003

[20] [SQISHQL]: Miller, Libby; Seaborne, Andy; Reggiori, Alberto, Three Implementations of SquishQL, a Simple RDF Query Language, ,2002

[21] [STUCK, 2003]: Heiner Stuckenschmidt, Ontology-Based Information in Dynamic Environments, Proceedings of Workshops on Enabling Technologies: Infrastructure for Collaborative Enterprises (WETICE'03),2003

[22] [Pomian, 1996] Pomian J. (1996). Mémoire d'entreprise: techniques et outils de la gestion du savoir. Éd. Sapientia.

[23] [DAVEN, 2000]: Thomas H. Davenport, Laurence Prusak, Working Knowledge, ISBN:1578513014, May, 2000

[24] [ACITY, 2002]: AgentCities Consortium, AgentCities.NET Project IST-2000-28384, 2002, http://www.agentcities.org/EUNET/http://www.agentciti es.org/EUNET/

[25] [AGLET, 2002]: IBM, Open Source Community, Aglet Portal, 2002, http://aglets.sourceforge.net/

[26] [GANDON, 2002]: Gandon, F., 2002. Distributed Artificial Intelligence and Knowledge Management: Ontologies and Multi-agent Systems for a Corporate Semantic Web (Thèse).

[27] [ALINK, 2002]: AgentLink II Members, AgentLink II EU Project, 2002, http://www.agentlink.org/

[28] [GRUBER, 1993] : A translation approach to portable ontology specifications Knowledge Acquisition, 5(2):199-220, 1993.

[29] [AND02]: JAMES J. ANDERSON, AN AGENT-BASED EVENT DRIVEN FORAGING MODEL, NATURAL RESOURCE MODELING, Volume 15, Number 1,2002

[30] [AUML]: FIPA modeling Group, Agent-based Unified Modeling Language - AUML, 2004 , http://www.auml.org/

[31] [BAL00A]: Zoltán BALOGH, Michal LACLAVÍK, Ladislav HLUCHÝ, Model of Negotiation and Decision Support for Goods and Services, ASIS 2000, Czech Republic,2000

[32] [BAL00B]: Zoltán BALOGH, Michal LACLAVÍK, Ladislav HLUCHÝ, Multi Agent System for Negotiation and Decision Support, Herlany 2000, Slovakia,2000

[33] [BAL, 2003A]: Zoltan Balogh, Michal Laclavik, Ladislav Hluchy, Use of Ontology in Virtual Organizations for Environment Risk Management, 11th ERCIM Environmental Modeling Group Workshop 2003, Smolenice, 